\title{
The Effectiveness of Computer Supported Versus Real Laboratory Inquiry Learning Environments on the Understanding of Direct Current Electricity among Pre-Service Elementary School Teachers
}

\author{
Mustafa Başer \\ University of Mustafa Kemal, Antakya, TURKIYE \\ Soner Durmuş \\ University of Abant Izzet Baysal, Bolu, TURKIYE
}

The purpose of this study was to compare the changes in conceptual understanding of Direct Current Electricity (DCE) in virtual (VLE) and real laboratory environment (RLE) among pre-service elementary school teachers. A pre- and post- test experimental design was used with two different groups. One of the groups was randomly assigned to VLE (n $=42$ ) and the other to RLE ( $\mathrm{n}=38$ ). Participants in the VLE group used computer simulations to perform the given tasks, whereas those in the RLE group used real laboratory apparatus. Before the treatment, all the students administered the Direct Electric Circuits Concepts Test (DIRECT). Pre-test analyses show that there was no significant difference between the two groups in terms of understanding DCE. After completing three week physics by inquiry based treatment, the DIRECT was readministered as a post-test. Results showed that both groups showed the same effects on acquisition of scientific concepts.

Keywords: CAL Systems; Virtual Laboratory; Inquiry Learning; Pre-Service Teachers

\section{INTRODUCTION}

Many researchers in science education indicated that students from different age groups and levels have difficulties in acquiring the concepts in physics (e.g., Baser, 2006a; Engelhardt \& Beichner, 2004; Peters, 1982). These difficulties arise from the fact that students

Correspondence to: Mustafa Basser, Assoc. Professor in Science Education, Mustafa Kemal Universitesi, Egitim Fakultesi, BOTE, Antakya, Hatay-TURKIYE

E-mail: baser.mustafa@yahoo.com construct their own concepts by interacting with the physical world. In general, these constructions are usually not consistent with scientifically accepted ideas (Vosniadou et al., 2001). Researchers use different names for these scientifically inconsistent ideas, namely preconceptions, misconceptions, alternative conceptions, intuitive conceptions, and so on. (Aguirre, 1998; Tsai \& Chou, 2002; Eryilmaz, 2002; Sherin, 2006). In the current study, the term called alternative conceptions is preferred for referring to the mistaken answers given by students, their ideas about particular situations, and to their fundamental beliefs about how the world works (Dykstra, Boyle, \& Monarch, 1992). 


\section{State of the literature}

- Although there are a number of studies in science education literature for evaluating the effect of real laboratory environment and virtual laboratory environment in both of which students perform traditional confirmatory experiments, there only a few studies that compares when inquiry learning is the primary teaching method in both environments.

- On the other hand, most of the studies found in the literature do not include gender comparison in both learning environments.

- Lastly, the comparison of delayed effects of real and virtual learning environments are rare in the current science education literature.

\section{Contribution of this paper to the literature}

This study contributes to the current science education literature in three contexts:

- it explores the change in students understanding of electric concepts in technology rich inquiry learning environment,

- it finds out that female students perform better in technology rich learning environment,

- it discloses that conceptual change is durable when inquiry learning environment is implemented by both real and virtual learning environments.

Alternative conceptions related to different subjects of physics have been documented in the literature (e.g., Cepni \& Keles, 2006; Ma-Naim, Bar, \& Zinn, 2002; Maloney, O'Kuma, \& Hieggelke, 2001; Hestenes, Wells, \& Swackhamer, 1992). Changing alternative conceptions is not an easy task since these conceptions are very stable, well embedded in students' cognitive domain (Sungur, Tekkaya, \& Geban, 2001), and difficult to remove with traditional teaching methods (Eryilmaz, 2002). Thus, physics educators search for new methods to change these alternative conceptions. Although there is a number of perspectives in interpreting student conceptual change in physics (Chi, Slotta, \& De Leeuw, 1994; diSessa, 2002; Vosniadou, 2001), the most commonly implemented conceptual change models are mainly based on Piaget's cognitive disequilibrium notion (Tsai, 2003). A well-known conceptual change model is proposed by Posner et al. (Baser \& Geban, 2007). In this conceptual change model, students have to be confronted with a cognitive conflict induced by a discrepant event. Inquiry learning can be used to help students solve this cognitive conflict and construct their own conceptions by engaging students in scientific processes that encourage students to build a personal scientific knowledge which they can use to predict and explain their natural world (van Joolingen, de Jong, \& Dimitrakopoulou, 2007).
Researchers have revealed that inquiry-based learning could be facilitated effectively through the use of real laboratory experiments and/or the use of virtual laboratory experiments (Zacharia, 2007; Finkelstein et al., 2005). There were a few studies that investigate educational implications of using technology-rich inquiry environments (Waight \& Abd-El-Khalick, 2007). Therefore, this study is conducted in an attempt to fill in the gap in this area by investigating the relative effectiveness of inquiry learning through computer simulations and real experimentation on students' understanding of direct current electricity.

\section{Computer Supported Inquiry Learning}

Inquiry learning fosters conceptual change by engaging students in exploring the given tasks that are expected to lead them to state hypotheses, carry out experiments, create models and theories, and evaluate them as scientists do. The essence of this process is to carry out experiments that are usually done in real laboratory environment. On the other hand, computer simulations have the potential of giving students the chance to carry out experiments virtually as in the real laboratory environment (Finkelstein et al., 2005).

In the last two decades, computers have been used to create environments that engage learners in scientific inquiry (van Joolingen, de Jang, \& Dimitrakopoulou, 2007). They come up to the agreement that computerized inquiry learning has positive effect on students' conceptual understanding (Salovaara, 2005; Taasoobshirazi et al., 2006). However, there are a few studies comparing the achievement of students' performing tasks in real laboratory environment to that in virtual laboratory environment, in both of which inquiry learning is implemented (Zacharia, 2007). These studies support the view that virtual experimental environment has similar or better effect on students' conceptualization of scientific concepts when compared to real experimental environments (van Joolingen, de Jong \& Dimitrakopoulou, 2007; Zacharia, 2007).

In spite of the benefit of using computer simulations to enhance inquiry, there are some critical issues implementing computer supported inquiry learning. Although prior knowledge and computer literacy seem to be important for carrying out experiments in virtual learning environment, Wecker, Kohnle, and Fischer (2007) found that there was no significant relations between procedural computer-related knowledge and self-confidence in using the computer for the acquisition of knowledge. The same study also revealed that students that are more literate about computer acquired significantly less knowledge. According to Wecker, Kohnle, and Fischer (2007, p.141), "the dyad with higher familiarity with computers spent less time on the single elements for receptive use, which gave them little opportunity to elaborate on the information 
provided in these elements". Another issue that science educators should take into consideration is the gender bias in computer supported learning. It is generally accepted that technology is gender-neutral (Plumm, 2008). Contrary to this view, current research findings reveal that there are significant gender-related differences in performance and interaction style in computerized learning environments. Although computer supported learning environments have the potential of offering democratic and equal opportunities, the evidence suggests that this claim is no longer true because of the fact that interaction through electronic channels does not consider the social complexity and gender imbalance which already exists within society (Gunn et al., 2002). However, the findings of Mayer-Smitha, Pedrettib, and Woodrowa (2000) indicate that gender issue should not be seen as one that promotes student engagement and success. More significant than gender are the issues concerning how science and technology-rich learning environments should be structured, and what pedagogical practices need to be used. Hence, computer-supported learning environment facilitating inquiry learning should be designed so as to offer equal opportunities (Gunn, 2003). This kind of learning environment will not be beneficial only to males but also to females (Hakkarainena \& Palonen, 2003). Physics by inquiry curriculum is designed with pedagogy to make students active while constructing their own knowledge.

\section{Studies in Direct Current Electricity}

Since concepts in direct current electricity such as current, potential difference, complete circuit, and power dissipated within circuit element are abstract (Choi, 2004), students develop many alternative conceptions related to these concepts. There are many studies that investigate these alternative concepts from different countries and for different age groups (Baser, 2006b; Cepni \& Keles, 2006; Periago \& Bohigas, 2005; Engelhardt \& Beichner, 2004; Lee \& Law, 2001; Shipstone et al., 1998; McDermott \& Shaffer, 1992).

Earlier studies naturally deal with identifying students' alternative conceptions related to electricity. For example, Fredette and Lochhead (1980) found that most young students consider that current can be carried by a single wire from the positive terminal of the battery to a bulb to shine it and thus there is no need to connect another wire from battery to bulb. However, some students consider that current coming from positive and negative terminal of the battery should be met at the bulb to shine it and therefore they consider that two wires are needed (Osborne, 1983). Students having these kinds of alternative conceptions also consider that current flows in one direction around the circuit and is used up so that less is available to other bulbs in the circuit (Shipstone, 1984).
Understanding electric diagrams and interpreting a short circuit are other sources of difficulty for students. For example, they tend to analyze only the modified part of the circuit rather than the whole circuit if they are asked to analyze the circuit in case any change takes place in a part of the circuit (Cohen, Eylon, \& Ganiel, 1983; Engelhardt \& Beichner, 2004).

A recent study by Engelhardt and Beicher (2004, p.100) provides an extensive list of students' difficulties and alternative conceptions related to direct current electricity. Here is the list of some examples: students are unable i) to consider that there is no potential difference in an open circuit, ii) to understand the functional two-endedness of circuit elements, iii) to interpret pictures and diagrams of a variety of circuits including series, parallel, and combinations of the two, iv) to understand and apply conservation of current (conservation of charge in the steady state) to a variety of circuits, and so on. Even, these misconceptions do exist on in- and pre- service physics teachers (Kucukozer \& Demirci, 2008).

Recent studies aim to change these alternative conceptions using different teaching strategies. For example, Tsai (2003) investigate the effectiveness of conflict maps on refining students' alternative conceptions about simple series electric circuits and conclude that conflict maps have positive effect. Chiu and Lin (2005) used analogies for promoting conceptual change and show that the use of analogies helped students refine their misconceptions concerning electricity. Conceptual change texts can also be used to change students' alternative conceptions related to electricity as in the study of Carles and Andre (1992). Science educators started to integrate computer simulations as the new technologies come to scene. Although computer simulations seem to be a good alternative for gaining concepts in electricity (e.g., Ronen \& Eliahu, 2000), science educators are aware that students may benefit better from real than virtual laboratory experiments (e.g., Srinivasan et al., 2006). The studies have begun to focus on the effectiveness of computer simulations in enhancing students' conceptual understandings of electric circuits. For example, Baser (2006a) used an open source software, called Qucs, where students were asked to analyze certain electric circuits to produce numerical or qualitative answers to the given questions, and then to use Qucs to simulate the circuit and check their answers. This study revealed that open source software simulations are effective on promoting conceptual change in direct current electricity. On the other hand, if conceptual change strategies are facilitated through computer simulations, they give rise to better acquisition of conceptual change of direct current electricity concepts than the confirmatory simulation (Baser, 2006b). In another study, Olde (2004) concludes that if students are 
encouraged to finish tasks using computer simulations, these simulations strengthen their domain knowledge by retrieving and explaining problem solving steps, and focusing on the dynamic characteristics of the simulated circuits.

The comparison of real versus virtual experiments is a new issue in science education. Jaakkola, Nurmi, and Lehtinen (2005) used computer-simulation software to compare its effectiveness on the understanding of electric circuits to real laboratory experiments. His results show that the computer simulations improve students' understanding of electric circuits when compared to the laboratory work. According to the results of Finkelstein et al. (2005), students using computer simulations instead of real apparatus perform better on conceptual questions related to simple circuits. Recently, Zacharia (2007) investigated the value of combining real lab experiments with virtual lab experiments with respect to changes in students' conceptual understanding of concepts in electric circuits. He found that this combination enhanced students' conceptual understanding more than the use of real lab experiments alone. Van Joolingen, de Jong, and Dimitrakopoulou (2007) summarize the findings of previous studies regarding the use of computersupported inquiry learning in science and argue that the comparison of real to virtual is a current issue and that there is a need for further studies comparing real to virtual lab experiments in inquiry learning.

\section{Research Method}

\section{Purpose}

The purpose of this study is to investigate the effectiveness of virtual laboratory environment (VLE) when compared to real laboratory environment (RLE) on students' conceptual understanding of electric circuits both implementing physics by inquiry curriculum developed by McDermott et al. (1996). The research questions are as follows:

1. Is there a significant difference between preservice elementary school teachers' understandings of direct current electricity concepts in VLE and RLE groups?

2. What is the contribution of students' attitudes toward physics and their science process skills to variations in pre-service elementary school teachers' understandings of direct current electricity concepts?

3. Is there a significant contribution of gender and interaction between genders, their attitudes towards physics, and modes of treatments to the variations in pre-service elementary school teachers' understandings of direct current electricity concepts?

4. Is there a significant difference between long-term effects of VLE and RLE on pre-service elementary school teachers' understandings of direct current electricity concepts?

\section{Participants}

The participants were 87 pre-service elementary school teachers enrolled in two classes of science education course at Abant Izzet Baysal University in Turkey. Seven participants were excluded from analyses since their data were missing either in the post test or retained test or they missed at least one week of instructions. None of the participants received physics course in electricity at the university. For most of the participants $(n=67)$, it was the first time that they were facing the direct current electricity concepts such as potential difference, current and power dissipation in circuit element. The participants of this study ranged in age from 19 to 22 years. Participants' native language

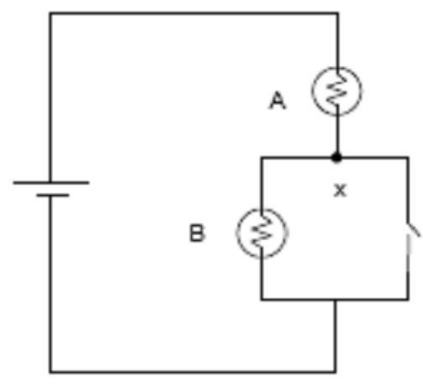

(A)

Figure 1. (A) Circuit diagram (B) Constructed circuit in CCK

(B)

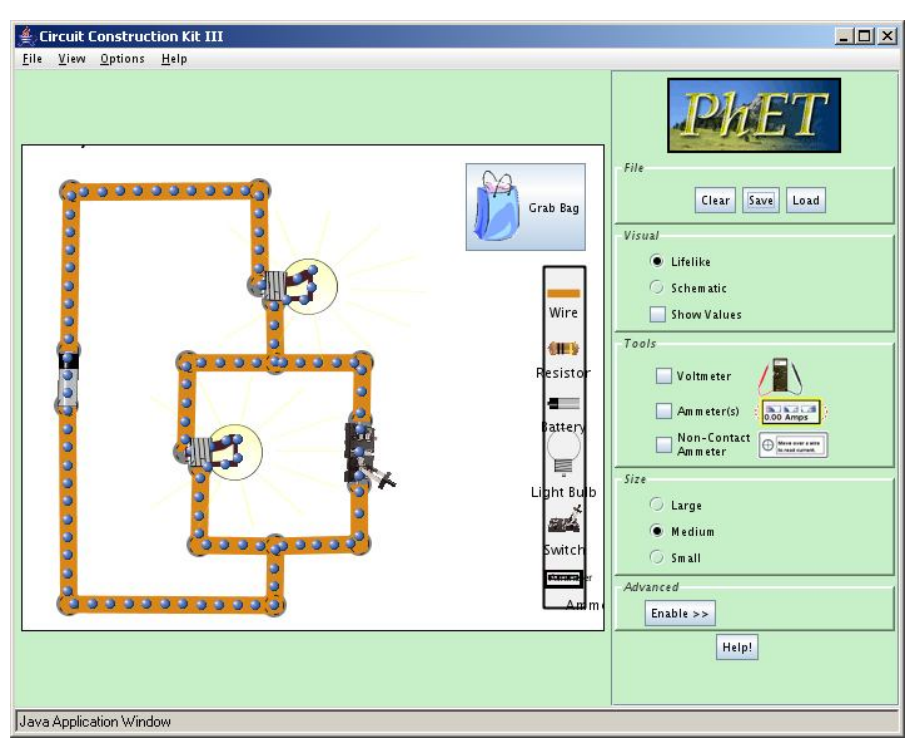


and language of instruction were Turkish. In both groups, students worked in pairs. The study lasted twelve hours in three sessions (one session per week). Each of the two instructional methods was randomly assigned to one class after the participants were already in the class. The VLE group consisted of 42 students (30 female, 12 male) and there were 38 students (23 female, 15 male) in the RLE group. Both groups were instructed by the first author of this study.

\section{Instruments}

\section{Determining and Interpreting Resistive Electric Circuit Concepts (DIRECT)}

The authors of the present study found few tests on DC electric circuits (e.g., Cohen, Eylon, \& Ganiel, 1983; Dupin \& Johsua, 1987; Millar \& King, 1993) in the related literature, but these tests were mostly developed either for a research tool or curriculum assessment instrument, not for a general assessment tool. Hence, the scope of these tests restricted content, dealing with a single concept such as voltage or resistance. Engelhardt \& Beichner (2004) decided to develop DIRECT as to evaluate students' understanding of a variety of direct current resistive electric circuit concepts. In the present study, the authors decided to use DIRECT (v.1.2) to determine conceptual understandings of students in direct current electricity based on the following criteria: i) it is a test that can be used to diagnose both high school and university students' reasoning regarding to direct current resistive electric circuits (Engelhardt \& Beichner, 2004), ii) it can be used to evaluate students' progress in learning concepts in direct current electricity (Baser, 2006b), and iii) it is a useful pedagogical tool to assess student learning in an inquiry-based physics course (Ross \& Venugopal, 2005).

There are 11 objectives related to four sub-topics of direct current electricity in the test. The test contains 29 five alternative multiple choice (one item has four alternatives) conceptual items. The test is translated and adapted to Turkish by the first author. The translated version of the test is examined and verified by two physics instructors who have English proficiency. Reliability (KR20) of the Turkish version was found to be 0.71 . Therefore, the test can be used for group measurements. Some representative items from DIRECT were given in Appendix A. In order to investigate the effect of VLE and RLE on students' understandings of direct electric circuit concepts, DIRECT was administered as a pre and post test to all the participants in the study. Furthermore, DIRECT was given as a delayed post test to determine the delayed effect of the two modes of learning environment after three months.

\section{Physics Attitude Scale (PAS)}

Since attitudes toward the subjects investigated in the study are generally related to success (e.g., Chin \& Won, 2001; Baser \& Geban, 2007), students' attitude toward physics was controlled. This scale was developed by the first author of this study (Baser, 2003.). While the scale was constructed in the previous study, firstly students were asked to write down what they think about physics as a school subject. Then texts written by students were carefully analyzed and classified common ideas. The ideas put together to form the scale which was submitted to field expert. Their recommandations were taken into consideration to make the scale better. Finally 15 Likert type items were constructed and applied to students who tooks physics for determining its reliability. IIts reliability was found as 0.83 . This test was applied to students in both groups before the treatment to determine students' attitudes towards physics. Some sample items were given in Appendix B.

\section{Science Process Skill Test (SPST)}

Students' science process skills play an important role on inquiry based curriculum for their achievements (Myers \& Dyer, 2006), so this measure was taken to control students' science process skills. Burns, Okey and Wise (1985) developed this test and it contains 36 fouralternative multiple-choice questions. Students in both groups took the test prior to the treatment. The reliability of the test was 0.81 . It measures basic skills to implement scientific inquiry methods such as identifying variables, identifying and stating the hypotheses, operationally defining, designing investigations and interpreting data. Some items from SPST were given in Appendix C.

The inclusion of covariates can increase statistical power because it accounts for some of the variability (Tabachnick and Fidell, 2001). Both measures of PAS and SPST were used as covariates for ANCOVA statistics to remove the effects of students' attitudes toward physics and their science process skills on their achievement related to concepts in direct current electricity.

\section{Treatment}

The module of electric circuits from physics by inquiry curriculum (PBI, McDermott \& The Physics Education Group, 1996) was translated and adapted to Turkish by the first author. The consistency of the Turkish form was reviewed by a physicist and two physics students, their recommendations were taken into consideration without changing the structure of PBI. Identical PBI curriculum was implemented in both groups. This study compares the effectiveness of two 
instructional conditions that differ only in the medium of experimentation. Students in the VLE group performed experiments using computer simulation software (Circuit Construction Kit, CCK), whereas students in the RLE group performed the same experiments using real laboratory instruments.

PBI curriculum was developed considering the basic tenets of constructivist views of cognitive development by McDermott and her colleagues (1996). Students bring some alternative conceptions based on their interactions with their environments to physics classes. PBI curriculum recognizes these conceptions and claims that these prior conceptions can be changed to scientifically accepted conceptions through experimentation. PBI curriculum generally uses discrepant events assuming that these events would induce cognitive conflict. A discrepant event is generally the physical experience that provides students with novel evidence to contradict their existing conceptions (Kang, Scharman, \& Taehee, 2004; p.73). Hence, PBI curriculum is specifically designed to be implemented in real laboratory environment. The concepts and relations are investigated in-depth in PBI curriculum rather than in broader sense. Students construct their own knowledge through a process of guided inquiry in which they work with simple experiments to make observations as scientist do by developing critical thinking and scientific reasoning skills. During this process, well-designed questions were asked to students for helping them understand the concepts being taught. The role of instructors is to intervene and ask more probing questions as to reveal what they have learned and to guide for further learning.

It was decided that the experiments in circuit module of PBI curriculum can be implemented with openended simulation software as with real laboratory apparatus. The simulation software used in this study to conduct experiments virtually was Circuit Construction Kit (CCK). CCK is developed by the Physics Education Technology project at the University of Colorado (http://phet.colorado.edu/web-pages/index.html).

Students can conduct experiments using CCK similar to real-life labs (Perkins et al., 2006). Connecting light bulbs, switches, resistors and wires to create desired direct current electric circuits are possible in CCK. For example, as a part of instruction in one question (see Fig. 1A), students are asked firstly to predict how brightness of the bulb A and B are affected if the switch is closed. Secondly, they are required to set the circuit up and check their answers. In CCK, this experiment can be done as in Fig. 1B.

If the computer simulation experiments are compared to real laboratory experiments, it can be claimed that computer simulation experiments have two advantages over real experiments: 1) Students have difficulties with the basic concept of electric circuits due to the fact that they can not see electric charge carriers (electrons) move through an electric wire (Pfister, 2004). CCK simulations offer opportunities to students to observe the electrons moving explicitly through circuit components. This may enable students to understand charge conservation and to be aware of the fact that the

Table 1. Means (M) and Standard Deviations (SD) of the Pre, Post, and Delayed Post Test Results of the DIRECT, SPST, and PAS

\begin{tabular}{|c|c|c|c|c|c|c|c|c|c|c|c|}
\hline \multirow[b]{3}{*}{ Group } & \multirow[b]{3}{*}{$\mathrm{N}$} & \multicolumn{6}{|c|}{ DIRECT } & \multicolumn{2}{|l|}{ SPST } & \multicolumn{2}{|l|}{ PAS } \\
\hline & & \multicolumn{2}{|l|}{$\overline{\text { Pre }}$} & \multicolumn{2}{|l|}{ Post } & \multicolumn{2}{|c|}{ Delayed post } & \multicolumn{2}{|l|}{ Pre } & \multicolumn{2}{|l|}{ Pre } \\
\hline & & $\mathrm{M}$ & SD & $\mathrm{M}$ & SD & $\mathrm{M}$ & SD & $\mathrm{M}$ & SD & $\mathrm{M}$ & SD \\
\hline VLE & 42 & 9.31 & 3.04 & 15.38 & 3.72 & 14.50 & 2.65 & 24.57 & 3.23 & 2.93 & 0.78 \\
\hline RLE & 38 & 9.74 & 2.94 & 15.45 & 3.32 & 13.50 & 3.44 & 23.97 & 3.67 & 3.07 & 0.61 \\
\hline
\end{tabular}

Table 2. ANCOVA Summary (Group vs. Achievement)

\begin{tabular}{llllll}
\hline Source & SS & df & MS & F & $P$ \\
\hline Treatment & 10.34 & 1 & 10.34 & 1.15 & 0.29 \\
Gender & 12.02 & 1 & 12.02 & 1.33 & 0.25 \\
Treatment * Gender & 102.52 & 1 & 102.52 & 11.36 & $0.00^{*}$ \\
Covariate (Attitude towards Physics) & 49.65 & 1 & 49.65 & 5.50 & $0.02^{*}$ \\
Covariate (Science Process Skills) & 77.03 & 1 & 77.03 & 8.54 & $0.01 *$ \\
Error & & & & & \\
\hline
\end{tabular}

${ }^{{ }^{2}}$ Significant $(\mathrm{p}<.05)$ 
brightness of bulb depends on the number and the speed of electrons, which indicates the amount of current flowing through the bulb. 2) Since it is nearly impossible to have identical bulbs (real bulbs with equal resistances), students may encounter unexpected results during real laboratory experiments. For example, they may observe unequal brightness of bulbs in series. This observation may strengthen their alternative conceptions or cause new alternative conceptions. On the other hand, since current and voltage relations are calculated through Kirchhoff's law in computer simulations, students always observed correct brightness of bulbs in series.

Srinivasan et al. (2006) argue that most students perceive computer simulations as fake. In order to convince students that both VLE and RLE experiments yield the same results, at the beginning of the instruction students in the VLE group are given the chance to experience with real bulb, battery and wire as to light the bulb. The same experiment is done with CCK as to compare with real experiment. Hence, students may have a sense that doing experiments in computer environment is not fake.

\section{RESULTS}

In order to investigate the effectiveness of the treatments on dependent variable, and to control the students' previous learning in direct current electricity concepts, their science process skills, and attitude toward physics before the treatment, three pre-tests (DIRECT, SPST, PAS) were administered to all of the participants. The descriptive statistics is presented in Table I. The alpha level for all statistical tests was 0.05.

ANOVA statistics implied that there was no significant difference between the two groups in terms of learning direct current electricity concepts $(\mathrm{F}(0.41)=0.53, \quad \mathrm{p}>0.05), \quad$ science process skills $(\mathrm{F}(0.60)=0.44 \mathrm{p}>0.05)$, and attitude toward physics $(F(0.85)=0.36 \mathrm{p}>0.05)$ at the beginning of treatment.

\section{Contribution of Treatment to Achievement in the Direct Current Electricity Concepts}

By controlling the effects of students' science process skills and their attitudes towards physics as covariates, the immediate effects of two different instructions on students' achievement related to direct electricity concepts were determined with ANCOVA after the treatment. The analysis of data is summarized in Table II. The results revealed that the post-test mean scores of the VLE group and RLE groups with respect to the achievement related to direct current electricity concepts were not significantly different $\left(\bar{X}_{V L E}=15.38, \overline{\mathrm{X}}_{\mathrm{RLE}}=15.45\right)$.
In the light of the findings of this study, it is seen that computer supported inquiry and real laboratory inquiry teaching have the same effect on students' understandings of direct current electricity. The participants both in the VLE and RLE groups showed significant gains in the mean scores of DIRECT. The post-DIRECT scores were significantly higher in both groups when pre-DIRECT scores were compared with post-DIRECT scores.

When all test questions in DIRECT were analyzed using t-test, there was only one question (question number 13) in which the participants in the RLE group outperformed the participants in The VLE group. In question number 13, students were asked to deduce the best schematic diagram for the given realistic circuit. Since the participants in the RLE group played with real batteries, bulbs and wires, they were accustomed to construct real circuit for the given schematic diagram. Also, there was another question (question 22) in which students were asked to infer realistic circuit for the given schematic diagram. The participants in the RLE group did still better on this question, but the difference was not significant. Since simulations enable students to observe movements of charges through circuit, it was assumed that the participants in The VLE group were expected to understand the conservation of charges in the circuit. In question 1, students were asked if charges are converted to light when the bulb lights. However, the participants in The VLE group did not significantly outperform the participants in The RLE group.

Contribution of Attitudes toward Physics and Science Process Skills to Achievement in the Direct Current Electricity Concepts

ANCOVA statistics revealed that the contribution of students' attitudes toward physics and science process skills to the variations in their achievements related to direct current electricity concepts were significant. Hence, it seems that attitudes of the participants toward physics and science process skills are accounted for significant variations in their achievement related to direct current electricity concepts in physics if they receive physics by inquiry curriculum.

\section{Contribution of Gender and Interaction between Gender and Treatment to Achievement in the Direct Current Electricity Concepts}

Analyses of data indicated that although interaction between gender and treatment differences significantly contributed to students' understandings of direct current electricity concepts, gender alone was not significantly accounted for students' understandings of direct current electricity concepts. This interaction could 


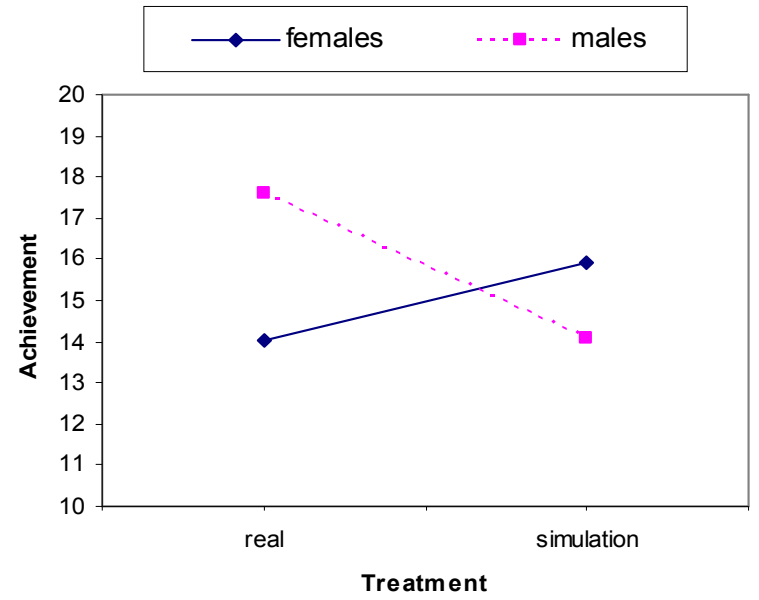

Figure 2. Achievement Test Scores by Gender

come from the gender difference in The RLE group (see Fig. 2).

Regarding gender differences in each group separately, the data indicated that there was a significant difference between the post-DIRECT scores of males and females in The RLE group $(\mathrm{t}=3.76, \mathrm{df}=36, \mathrm{p}=0.00$, $\overline{\mathrm{X}}_{\text {male }}=17.60 \bar{X}_{\text {female }}=14.04$ in favor of males, and none in The VLE group $(\mathrm{t}=1.45, \mathrm{df}=40, \mathrm{p}=0.16$, $\overline{\mathrm{X}}_{\text {male }}=14.08 \overline{\mathrm{X}}_{\text {female }}=15.90$ ). In the light of the findings of this study, males are observed to be superior in real laboratory experiments. The reason might be that male students might be more familiar to batteries, bulbs and wires than female students.

\section{Delayed Effects of VLE and RLE on Students' Understandings of Direct Current Electric Concepts}

DIRECT was re-administered to all participants of this study after three months to determine delayed effects of two modes of instruction on students' understandings of direct current electric concepts. ANOVA statistics indicated that there was no significant difference between the delayed post-test mean scores of the participants in The VLE group and the participants in The RLE group $(F(5.71)=0.02$, $\mathrm{p}<0.05)$. Although mean scores of students on the delayed post test were slightly less than those of students on the immediate post test, they were still significantly higher than those of pre test for both groups. This finding implies that physics by inquirybased instruction implemented in this study assures the durability of conceptual change, whether implemented either in virtual or real laboratory environments, at least in the short term.

\section{CONCLUSIONS}

The purpose of this study was to compare relative effectiveness of virtual laboratory inquiry learning environment to real laboratory inquiry learning environment on pre-service elementary school teacher' understandings of direct current electrical circuits. The participants in both groups followed the physics by inquiry curriculum in order to learn concepts in direct current electricity. While the participants in The VLE group utilized computer simulations to perform the given tasks, the participants in The RLE group used real laboratory apparatus to perform the same tasks. The analyses show that the achievements of participants in both groups are at the same level in terms of understanding concepts in electricity. Thus as an aswer for the first research questionof this study, it is observed that there is no difference for the participants between computer simulations or real laboratory apparatus. As a ansfer for the second and third research question of this study, it can be concluded that, based on the analyses of data, although science process skills, attitudes toward physics, and interactions between gender and treatment made significant contributions to the variations in achievement, gender difference and treatment did not. Tha last reseacrh question was about long term effect of modes of instruction on pre-service elementary school teachers' understandings of direct current electricity concepts. Analyses of data enable us to conclude that students in both virtual and real expereiments retained their understandings of concepts in direct current electricity at the same level.

\section{DISCUSSIONS}

The results showed that computer supported inquiry and real laboratory inquiry teaching had the same effect on students' understandings of concepts in direct current electricity. This finding is consistent with the works of Triona and Klahr (2007), Jaakkola, Nurmi, and Lehtinen (2005), and Choi and Park (2003). All of these studies indicated that computer simulations are as productive a learning tool as hands on equipments, given the same curricula and educational setting (Triona \& Klahr, 2003). One plausible explanation of why physical and virtual materials had equivalent effectiveness is that, because computer simulations capture important features of the instruction using real apparatus, physical materials are unnecessary (Triona \& Klahr, 2005). On the other hand, the study of Finkelstein et al. (2005) implied that students using computer simulations instead of real equipment perform better on conceptual questions related to simple circuits, and their ability to manipulate real circuits is high. The finding of Srinivasan et al. (2006) revealed that most of the students participated in the study perceived 
computer simulations as fake. In order to give students the chance to compare real with virtual experimentation in the current study, students in The VLE group were provided real bulb, battery, and wires to light the bulb in the first session of instruction. After that, they run the same experiment using computer simulation. Then, students in The VLE group were asked whether they perceived computer simulation as fake. All students agreed that real apparatus was essentially replaceable by computer simulation rather than seeing it as fake.

Constructivist learning approaches claim that students should be cognitively active while constructing their knowledge (Kitsantas, Baylor, \& Hu, 2001). Thus, whether an activity is carried out through computer simulations or real laboratory apparatus, being cognitively active is the main issue. Physics by inquiry curriculum encourages student to be mentally committed by guiding them through the process of constructing their models with which they can explain behaviors of electric circuits (Zacharia, 2007). Hence, it was observed that the participants in the VLE group actively built their knowledge of direct current electricity as similar to the participants in the RLE group. It seems that activities related to direct current electricity in physics by inquiry curriculum enabled students to foster conceptual change either through virtual or real laboratory environment. When the delayed effect of physics by inquiry curriculum is considered, students' success is promised to be durable both for the VLE and RLE groups.

The test used in this study to assess students' achievement related to direct current electricity was DIRECT. This test was used to measure the level of conceptual change in direct current electricity (e.g., Ates, 2005; Baser, 2006b). When the post-DIRECT test scores were compared to pre-DIRECT scores of the participants in both groups, the gains of participants in both groups were significant. Similar to the finding of this study, Ronen and Eliahu (2000) also concluded that simulations provide constructive feedback, help students realize their misconceptions and correct them. Hence, this might suggest that computer simulations promoted conceptual change as opposed to the claims of Finkelstein et al. (2005).

Physics by inquiry curriculum produced significantly higher post-test mean scores on the direct current electric concepts test (DIRECT) for both groups in comparison with their pre-test mean scores. The design of the physics by inquiry curriculum basically meets the conditions of conceptual change model offered by Posner et al. (1982). The conditions were as follows: (i) students should be dissatisfied with their current (alternative) conceptions; the new conception should be (ii) intelligible, (iii) plausible, and (iv) fruitful for students. The experiments usually begin with a contradictory question that enables students to recognize their misconceptions. Students are expected to answer the questions based on their previous experiences. Then, they were asked to construct the given circuit and validate their answers. If the result of the experiment is not the same as what students expected, a cognitive conflict that positions them in a state of reflection and resolution is invoked in them so that they become dissatisfied with their current conception (dissatisfaction). Students search and build a new conception on their own to solve the problem. Since they state their own conception in order to explain the behavior of the circuit, this new conception is not too complicated (intelligibility and plausibility). Afterwards, students are asked to predict the brightness of bulbs by using the newly constructed concept. If the result of the experiment is consistent with their newly constructed prediction, the new concept will be fruitful for them, i.e., will be helpful for explaining future problems. Baser (2006b) concluded that if students run experiments, which are related to simple electric circuits under the conditions of conceptual change model offered by Posner et al. (1982), through computer simulations they will have the opportunity to change their misconceptions. Therefore, as the result revealed, conceptual development of subjects following physics by inquiry curriculum is high regardless of medium of experimentation. However, the success of Posner's approach depends strongly on the wills and abilities of students to recognize and resolve the conflict (Planinic et al., 2005). As Ozdemir and Clark (2007), Dekkers and Thijs (1998), Dreyfus et al. (1990), and Elizabeth and Galloway (1996) argued, instructions based on cognitive conflict do not always promote conceptual change. The reason might be that students often refuse to accept ideas which are in direct conflict with their alternative concepts (Bergquist and Heikkinen, 1990).

Students' attitudes toward physics significantly contributed to their achievement related to direct electricity concepts. Thus, this study revealed that student' attitudes toward physics is a good predictor for the achievement related to direct current electricity concepts, which is consistent with previous studies (e.g., Baser \& Geban, 2007; Lightburn \& Fraser, 2007). Students' attitudes toward computer were not controlled in this study. Hence, further researchers should take into account students' attitudes toward computer in computer supported inquiry learning since students' achievement strongly depends on their attitude toward computer in computerized instruction. (e.g., Baser 2006b; Akcay et al., 2006; Chang, 2002). Students' science process skills are the other important factor affecting students' achievements. Since identifying variables, identifying and stating the hypotheses, designing experiments and interpreting data are basic skills to implement physics by inquiry curriculum, which are important components of science process skills, it is 
natural that students' science process skills contribute significantly to their achievement. Therefore, any physics teacher who considers implementing physics by inquiry curriculum should be aware of his/her students' science process skills. Another issue might be to investigate whether students' science process skills are affected by long-term implementation of physics by inquiry curriculum

When the contributions of treatment, gender, and interaction between the treatment and gender are considered, only interaction between the treatment and gender was observed to have made a significant contribution to the variance in achievement related to direct current electricity concepts. When the postDIRECT scores of males and females in the RLE and VLE groups are analyzed separately, males in The RLE group outperformed females in The RLE group. On the other hand, performances of males and females in The VLE group were the same on the post-DIRECT. Thus, it can be concluded that instruction in The VLE group is superior for females. This finding is supported in previous researches by comparing the success of males to females in inquiry based learning in real laboratory environment (e.g., Thijs \& Bosch, 1998; Wang \& Andre, 1991). Achievement of males compared to females in The RLE group might be explained with the common notion that males are more familiar to batteries, bulbs and wires than females. Although the difference between performances of males and females were not statistically different in The VLE group, females outperformed males. This finding is supported by the study of Mayer-Smith, Pedretti, and Woodrow (2000) in which they concluded that female students learning science through and with technology perform as well as or better than their male counterparts. As Akpan (2002) also found, virtual laboratory environment provides equal chances for both genders. Hence, this finding should be investigated in detail with larger sample size and with different subjects of physics.

What was it that made females successful in the VLE group? We attribute their success, in part, to the learning environment which provides an equal chance of experimentation with males. Ates (2005) found that achievement scores of male students were higher than those of female students when inquiry learning tasks were implemented through real batteries and bulbs. This result is totally consistent with the one obtained in the current study, that is, achievement scores of male students in RLE group is higher than those of female students, whereas in the VLE Group, contrary to this finding, achievement score of female students is higher than those of male students. This result is similar to the work of Mayer-Smitha, Pedrettib, Woodrowa (2000) who found that females were successful when no explicit intervention strategies were implemented to promote gender equitable learning with computer supported learning.

It is common that not all misconceptions related to direct current electricity can be challenged and hopefully changed through experimentation. Some other pedagogical means of physics education should be utilized. For example, analogies could be used to address some misconceptions in current electricity (Chiu \& Lin, 2005). On the other hand, conceptual change texts are one of the alternatives that can be accompanied with the regular classroom instruction for improving acquisition of qualitative concepts about simple electrical circuits (Wang \& Andre, 1991).

Contrary to general assumption that physical manipulation improves learning, Triona and Klahr (2007), and Finkelstein et al. (2005) preferred virtual to real manipulation. Based on the findings of our study, we conclude that students' conceptual understandings in electricity can be improved not only by physical manipulation but also by computer simulation.

\section{REFERENCES}

AAPT (1998). Goals of the Introductory Physics Laboratory. American Journal of Physics, 66(6), 483-485.

Aguirre, J. M. (1988). Student preconceptions about vector kinematics. The Physics Teacher, 26(4), 212-216.

Akcay, H., Durmaz, A., Tuysuz, C., \& Feyzioglu, B. (2006). Effects of Computer Based Learning on Students' Attitudes and Achievements towards Analytical Chemistry. The Turkish Online Journal of Educational Technology, 5(1), Article 6.

Akpan, J. P. (2002). Which Comes First: Computer Simulation of Dissection or a Traditional Laboratory Practical Method of Dissection. Electronic Journal of Science Education, 6(4), Article 1.

Ates, S. (2005). The effectiveness of the learning-cycle method on teaching DC circuits to prospective female and male science teachers. Research in Science and Technological Education, 23(2), 213-227.

Baser, M. (2003). Effect of instruction based on conceptual change activities on students' understanding of electrostatics concepts. Unpublished Ph.D. Dissertation, Middle East Technical University, Ankara, Turkey.

Baser, M., \& Geban, Ö. (2007). Effectiveness of conceptual change instruction on understanding of heat and temperature concepts. Research in Science \& Technological Education, 25(1), 115-133.

Baser, M. (2006a). Promoting conceptual change through active learning using open source software for physics simulations. Australasian Journal of Educational Technology, 22(3), 336-354.

Baser, M. (2006b). Effects of Conceptual Change and Traditional Confirmatory Simulations on Pre-Service Teachers' Understanding of Direct Current Circuits. Journal of Science Education and Technology, 15(5-6), 367381. 
Bergquist W. and Heikkinen, H., (1990), Student ideas regarding chemical equilibrium, Journal of Chemical Education, 67, 1000-1003.

Burns, J. C., Okey, J. R., \& Wise, K. C. (1985). Developments of an integrated process skill test: TIPS II. Journal of Research in Science Teaching, 22, 169-177.

Bybee, R. (2000). Teaching science as inquiry. In Inquiring Into Inquiry Learning and Teaching in Science (eds J. Minstrel\& E.H. Van Zee), pp. 20-46. American Association for the Advancement of Science (AAAS), Wasington, DC.

Carlsen, D., \& Andre, T. (1992). Use of a microcomputer simulation and conceptual change text to overcome student preconceptions about electric circuits. Journal of Computer-based Instruction, 19, 105-109.

Cepni, S., \& Keles, E. (2006). Turkish students' conceptions about the simple electric circuits. International Journal of Science and Mathematics Education, 4(2), 269-291.

Chang, C. Y. (2002). Does computer-assisted instruction + problem solving $=$ improved science outcome? A pioneer study. Journal of Educational Research, 95(3), 143150.

Chi, M. T. H., Slotta, J. D., and De Leeuw, N. (1994) From things to processes: a theory of conceptual change for learning science concepts. Learning and Instruction, 4, 2743.

Chin, T. Y., \& Wong, A. F. L. (2001). Pupils' Classroom Environment Perceptions, Attitudes and Achievement in Science at the Upper Primary Level. AARE 2001.

Chiu, M. H., \& Lin, J. W. (2005). Promoting fourth graders' conceptual change of their understanding of electric current via multiple analogies. Journal of Research in Science Teaching, 42(4), 429-464.

Choi, E., \& Park, J. (2003). Conditions for the Effective Use of Simulation and Its Application to Middle-School Physics Inquiry Activities. Journal of the Korean Physical Society, 42(3), 318-324.

Choi, K., \& Chang, C. (2004). The Effects of Using the Electric Circuit Model in Science Education. Journal of the Korean Physical Society, 44(6), 1341-1348.

Cohen, R., Eylon, B., \& Ganiel, U. (1983). Potential difference and current in simple electric circuits: A study of student's concepts. American Journal of Physics, 51(5), 407-412.

Dekkers, P.J.J.M., \& Thijs, G.D. (1998). Making productive use of students' initial conceptions in developing the concept of force. Science Education, 82(1), p.p. 31-52.

diSessa, A. A. (2002). Why "Conceptual Ecology" is a good idea. In M. Limon \& L. Mason (Eds.), Reconsidering conceptual change: Issues in theory and practice (pp. 29-61).The Netherlands: Kluwer.

de Jong, T. (2006). Computer simulations: technological advances in inquiry learning. Science 312, 532-533.

Dreyfus, A., Jungwirth, E., \& Eliovitch, R. (1990), Applying the "cognitive conflict" strategy for conceptual change some implications, difficulties, and problems. Science Education, 74, p.p. 555-569.

Duit, R., \& Treagust, D. F. (2003). Conceptual change: a powerful framework for improving science teaching and learning. International Journal of Science Education, 25(6), 671-688.

Dupin, J. J., \& Johsua, S. (1987). Conceptions of French pupils concerning electric circuits: Structure and evolution. Journal of Research in Science Teaching, 24(9), 791-806.

Dykstra, D. I., Boyle, C. F., \& Monarch, I. A. (1992). Studying Conceptual change in learning physics. Science Education, 76, 615-652.

Elizabeth, L.L., \& Galloway, D. (1996). Conceptual links between cognitive acceleration through science education and motivational style: A critique of Adey and Shayer. International Journal of Science Education, 18, p.p. 35-49.

Engelhardt, P., \& Beichner, R. (2004). Students understanding of direct current resistive electrical circuits. American Journal of Physics, 72(1), 98-115.

Eryilmaz, A. (2002). Effects of Conceptual Assignments and Conceptual Change Discussions on Students' Misconceptions and Achievement Regarding Force and Motion. Journal of Research in Science Teaching, 39(10), 1001-1015.

Finkelstein, N. D., Adams, W. K., Keller, C. J., Kohl, P. B., Perkins, K. K., Podolefsky, N. S., Reid, S., \& LeMaster, R. (2005). When learning about the real world is better done virtually: A study of substituting computer simulations for laboratory equipment. Physical Review Special Topics - Physics Education Research, 1(1) p. 010103.

Fredette, N., \& Lochhead, J. (1980). Student conceptions of simple circuits," Physics. Teacher, 18(3), 194-198.

Gunn, C. (2003). Dominant or Different? Gender Issues in Computer Supported Learning. Journal of Asynchronous Learning Networks, 7(1), 14-30.

Gunn, C., French, S., McLeod, H., McSporran, M., and Conole, G. (2002). Gender Issues in ComputerSupported Learning. Association for Learning Technology Journal, 10(1), 32-44.

Hakkarainena, K., and Palonen, T. (2003). Patterns of female and male students' participation in peer interaction in computer-supported learning. Computers and Education, 40, 327-342.

Hestenes, D., Wells, M., \& Swackhamer, G. (1992). Force concept inventory, The Physics Teacher, 30, 141-158.

Hewson, P. W. (1981). A conceptual change approach to learning science, European Journal of Science Teaching, 31, 933-946.

Jaakkola, T., Nurmi, S., \& Lehtinen, E. (2005). In quest of understanding electricity - Binding simulation and laboratory work together. Paper for AERA (American Educational Research Association) 2005 conference. Montreal, Canada, 11.-15.4.2005.

Kautz, C. H., Heron, P. R. L., Loverude, M. E., \& McDermott, L.C. (2005). Student understanding of the ideal gas law, Part I: A macroscopic perspective. American Journal of Physics, 73(11), 1055-163.

Kitsantas, A., Baylor, A. L., \& Hu, H. (2001). The Constructivist Planning Self-Reflective Tool: Improving Constructivist Instructional Planning. Educational Technology, 41(6), 39-43.

Klahr, D., Lara, L. M., \& Williams, C. (2007) Hands on what? The relative effectiveness of physical versus virtual materials in an engineering design project by middle school children. Journal of Research in Science Teaching, vol. 44(1), 183-203. 
Kucukozer, H. \& Demirci, N. (2008). Pre-Service and InService Physics Teachers' Ideas about Simple Electric Circuits. Eurasia Journal of Mathematics, Science \& Technology Education, 4(3), 303-311

Lee, Y., \& Law, N. (2001). Explorations in promoting conceptual change in electrical concepts via ontological category shift. International Journal of Science Education, 23(2), 111-149.

Lightburn, M. E., \& Fraser, B. J. (2007). Classroom Environment and Student Outcomes among Students Using Anthropometry Activities in High-School Science. Research in Science \& Technological Education, 25(2), 53-166.

Maloney, D. P., O’Kuma T. L., \& Hieggelke C. J. (2001). Surveying students' conceptual knowledge of electricity and magnetism, American Journal of Physics, 69, S12-S23 (Supplement).

Ma-Naim, C., Bar, V., \& Zinn, B. (2002). Integrating microscopic, macroscopic and energetic descriptions for a conceptual change in thermodynamics, paper presented at the Third European Symposium on Conceptual Change, Turku, Finland, 26-28 June.

McDermott L., \& Shaffer P. (1992). Research as a guide for curriculum development: an example from introductory electricity, Part I: investigation of student understanding. American Journal of Physics, 60, 994-1002.

McDermott L.C., \& The Physics Education Group. (1996). Physics by Inquiry.Wiley, NewYork.

Millar, R., \& King, T. (1993). Students' understanding of voltage in simple series electric circuits. International Journal of Science Education, 15(3), 339-349.

Mayer-Smitha, J., Pedrettib, E., and Woodrowa, J. (2000) Closing of the gender gap in technology enriched science education: a case study. Computers and Education, 35, 51-63.

Myers, B. E., \& Dyer, J. E. (2006). Effects of Investigative Laboratory Instruction on Content Knowledge and Science Process Skill Achievement Across Learning Styles. Journal of Agricultural Education Volume, 47(4), 5263.

Olde, C. V. (2004). Student-generated assignments about electrical circuits in a computer simulation. International Journal of Science Education, 26(7), 859-873.

Osborne, R. (1983). Towards modifying children's ideas about electric current. Research in Science and Technology Education 1(1), 73-82.

Ozdemir, G., \& Clark, D., B. (2007). An Overview of Conceptual Change Theories. Eurasia Journal of Mathematics, Science \& Technology Education, 3(4), 351-361.

Periago, M. C. \& Bohigas, X. (2005). A study of second-year engineering students' alternative conceptions about electric potential, current intensity and Ohm's law. European Journal of Engineering Education, 30(1), 71-80.

Perkins, K., Adams, W., Dubson, M., Finkelstein, N., Reid, S., Wieman, C., \& LeMaster, R. (2006). PhET: Interactive Simulations for Teaching and Learning Physics. The Physics Teacher, 44(1), 18-23.

Peters, P. C. (1982). Even honors students have conceptual difficulties with physics. American Journal of Physics, 50(6), 501-508.

Pfister, H. (2004). Illustrating Electric Circuit Concepts with the Glitter Circuit. The Physics Teacher, 42, 359-363.
Planinic, M., Krsnik, R., Pecina, P. Susac, A. (2005). Overview and Comparison of Basic Teaching Techniques That Promote Conceptual Change in Students. A paper presented at the First European Physics Education Conference, Bad Honnef, July 4-7 ,2005, Germany.

Plumm, K. M. (2008). Technology in the classroom: Burning the bridges to the gaps in gender-biased education. Computers and Education, 50(3), 1052-1068.

Posner, G., J., Strike, K. A., Hewson, P. W., \& Gertzog, W. A. (1982). Accommodation of a scientific conception: Toward a theory of conceptual change. Science Education, 66, 211-227.

Ronen, M., \& Eliahu, M. (2000). Simulation - a bridge between theory and reality: the case of electric circuits. Journal of Computer Assisted Learning, 16, 14-26.

Ross, R., \& Venugopal, P. (2005). Work in Progress -An Assessment of Inquiry-Based Activities in a Second Semester Introductory Physics Laboratory, paper presented at the 35th ASEE/IEEE Frontiers in Education Conference, Indianapolis, Indiana, October 19-22, 2005.

Salovaara, H. (2005). An exploration of students' strategy use in inquiry-based computer-supported collaborative learning. Journal of Computer Assisted Learning 21 (1), 3952.

Sherin, B. (2006). Common Sense Clarified: The Role of Intuitive Knowledge in Physics Problem Solving. Journal of Research in Science Teaching, 43(6), 535-555.

Shipstone, D. M., \& Rhöneck, C. von and Jung, W. and Kärrqvist, C. and Dupin, J. J. and Joshua, S. and Licht, P. (1988) A study of students' understanding of electricity in five European countries. International Journal of Science Education, 10(3), 303 - 316.

Shipstone, D. M. (1984). A study of children's understanding of electricity in simple DC circuits. European Journal of Science Education, 6(2), 185-198.

Srinivasan, S., Perez, L.C., Palmer, R.D., Brooks, D.V., Wilson, K., \& Fowler, D. (2006). Reality versus Simulation. Journal of Science Education and Technology, 15(2), 137-141.

Sungur, S., Tekkaya, C., \& Geban, O. (2001). The contribution of conceptual change texts accompanied by concept mapping to students understanding of human circulatory system. School Science and Mathematics, 101(2), 91-101.

Taasoobshirazi, G., Zuiker, S. J., Anderson, K.T., \& Hickey, D.T. (2006). Enhancing Inquiry, Understanding, and Achievement in an Astronomy Multimedia Learning Environment. Journal of Science Education and Technology, 15(5), 383-395.

Tabachnick, B. G., \& Fidell, L. S. (2001). Using Multivariate Statistics (fourth edition), Allyn and Bacon: MA, USA

Thijs, G. D., \& Bosch, G. M. (1998). Cognitive effects of science experiments focusing on student's preconceptions of force: a comparison of demonstrations and small group practicals. International Journal of Science Education, 36, 526 - 527.

Triona, L. M., \& Klahr, D. (2007). Point and Click or Grab and Heft: Comparing the Influence of Physical and Virtual Instructional Materials on Elementary School Students' Ability to Design Experiments. Cognition and Instruction, 21(2), 149-173. 
Tsai, C. C., \& Chou, C. (2002). Diagnosing students' alternative conceptions in science. Journal of Computer Assisted Learning, 18(2), 157-165.

Tsai, C. C. (2003). Using a conflict map as an instructional tool to change student alternative conceptions in simple series electric-circuits. International Journal of Science Education, 25(3), 307-327.

van Joolingen, W.R., de Jong, T., \& Dimitrakopoulou, A. (2007). Issues in computer supported inquiry learning in science. Journal of Computer Assisted Learning, 23 (2), 111119.

Vosniadou, S., Ioannides, C., Dimitrakopoulou, A., \& Papademetriou, E. (2001). Designing learning environments to promote conceptual change in science. Learning and Instruction 11(4-5), 381-419.

Waight, N., \& Abd-El-Khalick, F. (2007). The Impact of Technology on the Enactment of "Inquiry" in a Technology Enthusiast's Sixth Grade Science Classroom. Journal of Research in Science Teaching, 44(1), p154-182.

Wang, T., \& Andre, T. (1991). Conceptual change text versus traditional text and application questions versus no questions in learning about electricity. Contemporary Educational Psychology, 16(2), 103-116.

Wecker C., Kohnle C., \& Fischer F. (2007). Computer literacy and inquiry learning: when geeks learn less. Journal Computer Assisted Learning, 23(2), 133-144.

Zacharia, Z. C. (2007). Comparing and combining real and virtual experimentation: an effort to enhance students' conceptual understanding of electric circuits. Journal of Computer Assisted Learning, 23(2), 20-132. 
Appendix-A: Some Items from Direct (Engelhardt And Beichner, 2004)

1) Which circuit or circuits have the greatest energy delivered to them per second?
(A) Circuit 1
(B) Circuit 2
(C) Circuit 3
(D) Circuit $1=$ Circuit 2
(E) Circuit 2 = Circuit 3
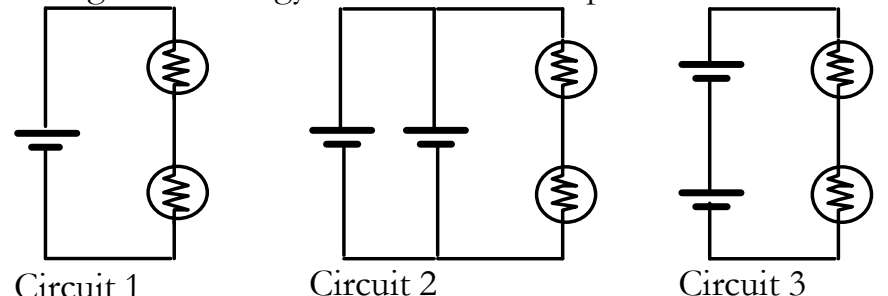

2) Compare the brightness of the bulb in circuit 1 with that in circuit 2 . Which bulb is brighter?
(A) Bulb in circuit 1 because two batteries in series provide less voltage
(B) Bulb in circuit 1 because two batteries in series provide more voltage
(C) Bulb in circuit 2 because two batteries in parallel provide less voltage
(D) Bulb in circuit 2 because two batteries in parallel provide more voltage
(E) Neither, they are the same

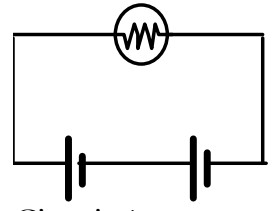

Circuit 1

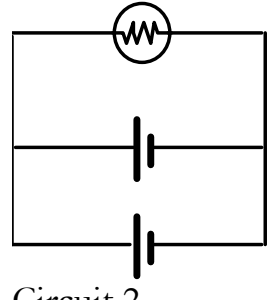

Circuit 2

3) Which circuit(s) will light the bulb? (The other object represents a battery.)
(A) Circuit 1
(B) Circuit 2
(C) Circuit 3
(D) Circuits 1 and 3
(E) Circuits 1, 3, and 4

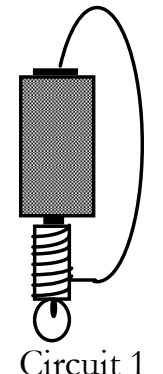

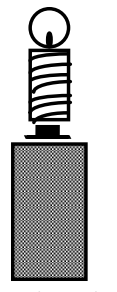

Circuit 2

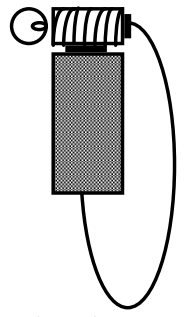

Circuit 3

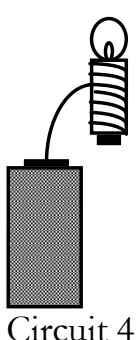


Appendix-B: Some Items from Physics Attitude Scale

In the blank provided in front of the statements about physics, please indicate whether you Totally Agree (TA), Agree (A), have no decision (ND), Disagree (D), or Totally Disagree (TD).

1. I like to learn more topics in Physics.

2. I get bored when I study Physics

3. I like to attend physics lessons.

_ 4.I am not interested in participating discussions related to physics subject

\section{Appendix-C: Some Items from Science Process} Skill Test (Burns, Okey and Wise, 1985)

1. Jim thinks that the more air pressure in a basketball, the higher it will bounce. To investigate this hypothesis he collects several basketballs and an air pump with a pressure guage. How should Jim test this hypothesis?

A) Bounce basketballs with different amounts of force from the same height.

B) Bounce basketballs having different air pressure from the same height.

C) Bounce basketballs having the same air pressure at different angles from the floor.

D) Bounce basketballs having the same amount of air pressure from different heights.

2. The effect of width of wheel on ease of rolling is being studied by a science class. The class puts wide wheels onto a small cart and lets they roll down an inclined ramp and then across the floor. The investigation is repeated using the same cart but this time fitted with narrow wheels.

How could the class measure ease of rolling?

A) Measure the total distance the cart travels.

B) Measure the angle of the inclined ramp.

C) Measure the width of each of the two sets of wheels.

D) Measure the weight of each of the carts. 